\title{
$\mathrm{R} C \& \mathrm{C}$
}

\section{GESTÃO E SUSTENTABILIDADE AMBIENTAL: ESTUDO EM UM ÓRGÃO PÚBLICO DO ESTADO DE SANTA CATARINA}

\author{
ENVIRONMENTAL MANAGEMENT AND SUSTAINABILITY: A STUDY IN A \\ PUBLIC AGENCY OF THE STATE OF SANTA CATARINA
}

Recebido em 08.12.2012 | Aceite final em 12.11.2013 |

Nota: este artigo foi aceito pelo Editor Jorge Eduardo Scarpin e passou por uma avaliação double blind review

A reprodução dos artigos, total ou parcial, pode ser feita desde que citada a fonte.

\section{PAULA DE SOUZA}

Acadêmica do curso de Ciências Contábeis | Universidade Federal de Santa Catarina | Campus Universitário Reitor João David Ferreira Lima | Trindade | Florianópolis-SC | CEP 88040-970 | Caixa-postal 476 | Telefone (48) 3331-6505 | Email: pauladesouza1604@gmail.com |

\section{ELISETE DAHMER PFITSCHER} Doutora em Engenharia de Produção | Universidade Federal de Santa Catarina | Professora da Universidade Federal de Santa Catarina | Campus Universitário Reitor João David Ferreira Lima | Trindade | Florianópolis-SC | CEP 88040-970 | Caixa-postal 476 | Telefone (48) 3331-6505 | E-mail: elisete@cse.ufsc.br |

\section{RESUMO}

Nas últimas décadas, a população tem exigido políticas de controle, preservação e recuperação ambiental por parte das organizações. Dessa maneira, os eventos ambientais precisam ser analisados de modo a produzirem informações necessárias para as decisões de gestão ambiental. Por tal razão, as informações ambientais devem ser gerenciadas por sistemas de gestão ambiental, a fim de possibilitar um diagnóstico confiável dos fatos ambientais que impactam o meio ambiente. Nesse contexto, este trabalho tem por objetivo geral verificar a gestão e sustentabilidade ambiental de um Órgão Público do Estado de Santa Catarina. Realizou-se uma análise de conteúdo, a partir das informações obtidas nos relatórios publicados no sítio do Órgão e da lista de verificação da terceira etapa do SICOGEA - Geração 2 com 76 questões, com aplicação in loco. O processo de identificação dos critérios e subcritérios que compõem a referida lista são definidos conforme literatura nacional e internacional e legislação pertinente. Os resultados apontaram que o Órgão em estudo está em um nível regular de desempenho ambiental no percentual de $49,32 \%$, o que indica que as práticas ambientais aplicadas estão mais destinadas a atender a legislação acerca da gestão e sustentabilidade ambiental. Os grupos- 
chaves Fornecedores/Compras, Prestação de serviço, Indicadores contábeis ambientais e Indicadores gerenciais, obtiveram os respectivos desempenhos ambientais: $36,67 \%$ (fraco), 59,26\% (regular), 45,00\% (regular) e $37,14 \%$ (fraco). No intuito a melhorar o desempenho dos dois menores índices de eficiência ambiental do Órgão em estudo, sugere-se que para 2013 o Órgão público de Santa Catarina forme um cadastro de fornecedores e licitações de bens e serviços com base em critério sustentáveis, a fim de obter uma conduta sustentável dos fornecedores e utilize um sistema de gestão ambiental específico, para que tenha um maior controle sobre as ações sociais e ambientais.

Palavras-chave: Gestão e Sustentabilidade Ambiental. Órgão Público. Estado de Santa Catarina.

\begin{abstract}
In recent decades, the population has demanded control policies, preservation and environmental remediation by organizations. Thus, environmental events need to be analyzed in order to produce information needed for environmental management decisions. For this reason, environmental information must be managed by environmental management systems, to enable a reliable diagnosis of the environmental facts that impact the environment. In this context, this work aims to verify the general management and environmental sustainability of a Public Agency of the State of Santa Catarina. We conducted a content analysis of information obtained from the reports published on the Organ and the checklist of the third stage of SICOGEA - Generation 2 with 76 questions, with application in the field. The process of identifying the criteria and subcriteria that make up this list are defined according to national and international literature and relevant legislation. The results showed that the Organ under study is in a regular level of environmental performance in the percentage of $49.32 \%$, which indicates that environmental practices are applied more designed to meet the legislation on the management and environmental sustainability. The key groups Suppliers / Purchasing, Service Delivery, environmental accounting indicators and indicators managerial, obtained their environmental performance: $36.67 \%$ (poor), $59.26 \%$ (regular), $45.00 \%$ (regular) and $3714 \%$ (poor) respectively. In order to improve the performance of the two lowest levels of environmental efficiency of the organ under study, it is suggested that for 2013 the Public Agency of Santa Catarina forms a registration of suppliers and biddings of goods and services based on sustainable criteria in order to achieve a sustainable conduct of suppliers and use a specific environmental management system, so you have greater control over the social and environmental actions.
\end{abstract}

Keywords: Environmental Management and Sustainability. Public Agency. State of Santa Catarina. 


\section{1 INTRODUÇÃO}

Nas últimas décadas, a população tem exigido políticas de controle, preservação e recuperação ambiental por parte das organizações. O desenvolvimento econômico e a crescente preocupação com o meio ambiente fazem emergir a necessidade de adoção de medidas sustentáveis.De um lado, os consumidores socialmente responsáveis atingem todos os nichos de mercado, em busca de ações inovadoras capazes de alcançar a responsabilidade social (SOARES; LANZARIN; PFITSCHER, 2011). De outro, instituições têm realizado trabalhos com consideráveis melhorias de desempenho ambiental em suas atividades produtivas (BENETTI; FIORENTIN; LAVARDA, 2011).

Destarte, a preocupação com o meio ambiente está se tornando um quesito para a sobrevivência competitiva no setor privado e para a prestação de contas no setor público. Assim, as instituições públicas e privadas se veem pressionadas a controlar os registros dos impactos ambientais causados por suas atividades, objetivando a proteção ambiental. Muitas vezes os eventos ambientais precisam ser analisados de modo a produzirem informações necessárias para as decisões de gestão ambiental, haja vista que os custos da poluição ambiental e de exploração excessiva de recursos são enormes, e as perdas, em diversos casos, são irreversíveis (PRIZZIA, 2002).

Por tal razão, as informações ambientais devem ser gerenciadas por sistemas específicos de gestão ambiental, possibilitando um diagnóstico confiável dos fatos ambientais que impactam o meio ambiente. Dessa maneira, os sistemas de decisão ambiental figuram como ferramentas de apoio frequentemente utilizados (POKORNY, 2006). Ademais, convém esclarecer que os sistemas ambientais são instrumentos de gestão que podem auxiliar na tomada de decisões das instituições públicas e privadas. Tal auxílio dos sistemas é justificável, tendo em vista que proporcionam melhorias nos processos e facilitam a resolução de eventuais problemas.

Nesse contexto, obtém-se a pergunta de pesquisa que direciona este artigo: de que forma um Órgão Público do Estado de Santa Catarina está contribuindo para a gestão e sustentabilidade ambiental? No intuito a responder a questão-problema, tem-se o objetivo geral do trabalho, qual seja, verificar a gestão e sustentabilidade ambiental de um Órgão Público do Estado de Santa Catarina. Para atingir o objetivo geral, foram definidos os seguintes objetivos específicos: (i) analisar as contribuições ambientais por meio da fase investigação e mensuração do Sistema Contábil Gerencial Ambiental (SICOGEA - Geração 2); (ii) propor um plano resumido de gestão ambiental para o referido Órgão; e (iii) verificar as estratégias ambientais do Órgão Público estudado para com a sociedade.

O trabalho apresenta, além dessa introdução, a fundamentação teórica na seção 2 , os procedimentos metodológicos aplicados na seção 3 , análise dos resultados na seção 4 e, por desfecho, as conclusões na seção 5 .

\section{FUNDAMENTAÇÃO TEÓRICA}

A fundamentação teórica do estudo se inicia com abordagens acerca da gestão e sustentabilidade ambiental, da gestão e sustentabilidade ambiental no setor público, seguidas da explanação sobre sistemas de gestão ambiental. Por fim, são feitas exposições dos estudos anteriores concernentes a presente pesquisa.

\subsection{GESTÃO E SUSTENTABILIDADE AMBIENTAL}

A gestão ambiental está despendendo a atenção da sociedade desde as últimas décadas. Tal razão se justifica, pois a questão ambiental assumiu um posicionamento estratégico para as empresas que usufruem dos benefícios gerados a partir de comportamentos sociais e ecológicos. Da mesma forma, a sustentabilidade ambiental adquiriu cautela, uma vez que está relacionada ao impacto das atividades organizacionais sobre a sociedade, o que inclui saúde, bem-estar, ambientes urbanos, 
qualidade do ar e da água, congestionamento, impactos ecológicos, esgotamento ou manutenção dos recursos e poluição (KOPPENJAN; ENSERINK, 2009).

Nesse sentido, sustentabilidade é definida pela World Commission on Environment and Development da ONU (1987, p. 16) como a "habilidade de fazer o desenvolvimento sustentável, garantindo que atenda as necessidades dos presentes sem comprometer as futuras gerações de atenderem suas próprias necessidades". Segundo descreve Tachizawa (2004), a preocupação com questões ambientais e responsabilidade social faz com que as empresas procurem fornecedores que atendam aos seus requisitos éticos e, também, com que os insumos produtivos estejam em conformidade com os requisitos ambientais. Knickle (2012) reforça que a tecnologia tem sido certamente uma facilitadora da sustentabilidade por meio de softwares e coletas automatizadas de dados acerca da sustentabilidade.

De mais a mais, as ferramentas contábeis e financeiras podem auxiliar mutuamente, gerando benefícios tanto na gestão ambiental dos setores público e privado, quanto na contabilidade e nas finanças (MIA, 2005). Questões inerentes ao meio ambiente também afetam o governo. Este tem o papel de fiscalizar o cumprimento de leis, normas e regulamentos (HESS, 2009; CHIANG, 2010). Adicionalmente, Oliveira (2003) discorre que, além de fazer cumprir as normas ambientais, as instituições públicas de Porto Seguro, Icapuí e Fernando de Noronha investem em infraestrutura ambiental e institucional, desenvolvendo projetos que envolvem saneamento, abastecimento de água e restauração ambiental, entre outros. Portanto, a gestão ambiental deve ser utilizada como um instrumento de informações aos órgãos públicos, evidenciando os fatos ambientais ocorridos na prestação de contas aos cidadãos acerca dos efeitos provocados pelos serviços conferidos à sociedade.

\subsubsection{GESTÃO E SUSTENTABILIDADE AMBIENTAL NO SETOR PÚBLICO}

Nos últimos anos, a sociedade tem aumentado gradativamente a exigência de uma política de controle, preservação e recuperação ambiental por parte das organizações. Os consumidores dos produtos e serviços tendem a valorizar a oferta com qualidade aliada à responsabilidade ambiental. Com efeito, as organizações se veem pressionadas a implantarem uma gestão ambiental para controlar o impacto de suas atividades produtivas sobre o meio ambiente.

Da mesma maneira que instituições privadas, as públicas necessitam seguir o mesmo rigor da legislação no que diz respeito ao meio ambiente, isto quer dizer, atender às leis e aplicar a sustentabilidade ambiental o máximo que for viável (SALDANO; CASAGRANDE; UHLMANN, 2010).

Além da exigência da sociedade, está crescendo a pressão regulatória do governo, o que implica no aumento de esforços das organizações para avaliação do desempenho ambiental e das melhorias reais dos resultados encontrados. Adicionalmente, muitos modelos de avaliação de desempenho ambiental estão sendo propostos para atingir tais objetivos (LUNDBERG; BARLSFORS; FOLKESON, 2009). Nesse sentido, informações contábeis de natureza social e ambiental, provenientes dos setores público e privado, têm sido amplamente demandadas pela sociedade, que tem respondido com indicadores de recursos ambientais (CRUZ; MARQUES; FERREIRA, 2009).

No setor público, a avaliação do desempenho ambiental é uma problemática nova. Em que pese existir certa experiência no desempenho global de gestão, a avaliação ambiental geralmente está relacionada à contabilidade (RAMOS et al., 2009). Ademais, as organizações públicas operam em um ambiente político, lidando não só com eficiência e eficácia, mas também com justiça, responsabilidade e equidade (CARROLL, 2004). Adicionalmente, o setor público também é responsável por fornecer uma gama de serviços muitos dos quais têm implicações diretas para a sustentabilidade, como o desenvolvimento econômico e eliminação de resíduos (WILSON; GAME, 2006). 
De outra maneira, Moffat e Auer (2006) explicam que, para alcançar respostas às questões ambientais, o governo precisa promover benefícios de eco-eficiência, prevenção da poluição e outras ferramentas de gestão ambiental. Além disso, deve desenvolver políticas fortes que liguem os condutores de inovação para os desafios ambientais, em caminhos que levam as informações contábeis sistemáticas para auxílio na tomada de decisão.

Também existem diversas iniciativas que envolvem a implantação de práticas de gestão ambiental no setor público, como, por exemplo, sistemas de gestão ambiental (SGA), auditorias ambientais e avaliação de desempenho ambiental, incluindo mensuração e comunicação dos resultados. Entrementes, a maior parte dessas ações está centrada na adoção de um SGA, como afirmam Ramos et al. (2009). Arimura, Hibiki e Katayama (2008) acrescentam que, normalmente, o SGA do setor público consiste na formulação, planejamento, implantação e revisão das políticas ambientais, a qual se destina a ajudar as unidades para reduzir os impactos ambientais de suas operações. Por fim, acredita-se que esses sistemas sejam semelhantes aos sistemas de controle de gestão utilizado nas organizações, em que aborda o impacto da empresa no meio ambiente e que sugere mecanismos para a realização de práticas sustentáveis (LODHIA, 2003).

\subsection{SISTEMAS DE GESTÃO AMBIENTAL}

As organizações têm se preocupado em controlar os registros dos impactos ambientais causados por suas atividades produtivas, visando à melhoria das estratégias e, consequentemente, à proteção do meio ambiente. Por diversas vezes, os registros ambientais precisam ser analisados para resultar em informações adequadas às decisões de gestão ambiental. Nesse contexto, os sistemas de decisão ambiental figuram como ferramentas de apoio constantemente utilizados (POKORNY, 2006). Polaz e Teixeira (2009, p. 411-412) argumentam que

Um dos desafios da construção do desenvolvimento sustentável é criar instrumentos de mensuração capazes de prover informações que facilitem a avaliação do grau de sustentabilidade das sociedades, monitorem as tendências de seu desenvolvimento e auxiliem na definição de metas de melhoria.

Em face disso, os esforços devem se voltar para o controle dos gastos e da eficiência, além de definir critérios para estimar montantes ideais de gastos e de compreender a dinâmica dos dispêndios ambientais (TRIDAPALLI et al., 2011).

Por sua vez, as informações ambientais, gerenciadas por sistemas específicos de gestão ambiental, possibilitam um diagnóstico confiável dos fatos ambientais que impactam no meio interno e externo à organização. Não obstante, é necessário que além do exame dos indicadores ambientais, sejam definidos objetivos que eliminem os danos (SOUZA; RÁSIA; JACQUES, 2010).

Os SGA devem integrar informação de clientes, autoridades e organizações governamentais, bem como de novos negócios, para que os pontos negativos sejam mais facilmente identificados (POKORNY, 2006). Ao utilizar o SGA, as empresas devem associar informações ambientais aos custos no planejamento e nos processos de decisão, definindo de forma voluntária seus objetivos ambientais (CHEN; MONAHAN, 2010). Por outro lado, Ramos et al. (2007) inferem que, diferente das empresas privadas, as organizações públicas devem dar respostas às necessidades da sociedade, o que inclui informações sobre os aspectos ambientais. Da mesma forma, para Barata, Kligerman e Minayo-Gomez (2007), as empresas e instituições públicas, principalmente aquelas que têm como missão direta promover o bem-estar social, deveriam ser as primeiras a tomarem a iniciativa de implantar um eficiente SGA.

Nesse contexto, Thomson e Jackson (2007) relatam que as autoridades governamentais da Inglaterra usam uma gama de abordagens ambientais, como a disseminação de compras verdes, fornecedores de informações ou incentivo para adotar o SGA. Em suma, os SGA são instrumentos de gestão que 
auxiliam na tomada de decisões das instituições públicas e privadas. Sua utilização nos órgãos públicos se justifica na medida em que a população deve estar informada sobre os impactos ambientais envolvidos na prestação de serviços à sociedade.

\subsection{ESTUDOS ANTERIORES}

Verificou-se que alguns estudos nacionais e internacionais acerca da gestão e sustentabilidade ambiental foram realizados em diferentes setores e instituições, como por ser observado no Quadro 1.

Quadro 1: Estudos realizados anteriormente

\begin{tabular}{|c|c|c|}
\hline AUTORES & PUBLICAÇÃO & ESTUDO \\
\hline Lodhia (2003) & Internacional & $\begin{array}{l}\text { discussão dos resultados de entrevistas realizadas com contabilistas } \\
\text { na República das Ilhas Fiji, acerca das respostas sobre questões } \\
\text { ambientais; }\end{array}$ \\
\hline Bacelo et al. (2007) & Nacional & $\begin{array}{l}\text { avaliação dos impactos ambientais de um condomínio residencial } \\
\text { com aporte da Contabilidade Gerencial Ambiental; }\end{array}$ \\
\hline Limongi et al. (2008) & Nacional & $\begin{array}{l}\text { análise da gestão ambiental, por meio do nível de sustentabilidade } \\
\text { ambiental, de uma instituição de ensino; }\end{array}$ \\
\hline Rosa et al. (2008) & Nacional & $\begin{array}{l}\text { análise de como a Contabilidade Ambiental pode auxiliar na gestão } \\
\text { de clínicas hospitalares de saúde; }\end{array}$ \\
\hline $\begin{array}{l}\text { Arimura, Hibiki e } \\
\text { Katayama (2008) }\end{array}$ & Internacional & $\begin{array}{l}\text { análise dos efeitos de duas ações voluntárias ambientais sobre o uso } \\
\text { de recursos naturais, sólidos, geração de resíduos, água e } \\
\text { desperdício; }\end{array}$ \\
\hline $\begin{array}{l}\text { Silva, Rosa e Pfitscher } \\
\text { (2009) }\end{array}$ & Nacional & $\begin{array}{l}\text { verificação da importância da utilização da contabilidade no } \\
\text { processo de gestão ambiental de uma indústria do setor moveleiro; }\end{array}$ \\
\hline $\begin{array}{l}\text { Marques, Pfitscher e } \\
\text { Gallon (2009) }\end{array}$ & Nacional & identificação das práticas de gestão ambiental em uma policlínica; \\
\hline $\begin{array}{l}\text { Chen e Monahan } \\
(2010)\end{array}$ & Internacional & $\begin{array}{l}\text { análise dos impactos das políticas de controle de poluição em } \\
\text { diferentes decisões de uma empresa de produção planejamento e } \\
\text { controle de estoque; e }\end{array}$ \\
\hline Vargas et al. (2010a) & Nacional & análise do SICOGEA de uma empresa de Cosméticos. \\
\hline
\end{tabular}

Dessa maneira, extrai-se do Quadro 1 que diversas pesquisas objetivaram analisar impactos e recursos ambientais, nível de sustentabilidade, gestão ambiental e sustentabilidade ambiental em empresas e instituições. Adicionalmente, verificou-se que de 2003 a 2009 apenas 3 estudos com a utilização da metodologia SICOGEA foram realizados em órgãos públicos (VARGAS et al., 2010b). Além disso, de 2010 até o dia 04 de dezembro de 2012 nenhum outro trabalho foi publicado com aplicação nas respectivas instituições, conforme evidencia a Figura 1.

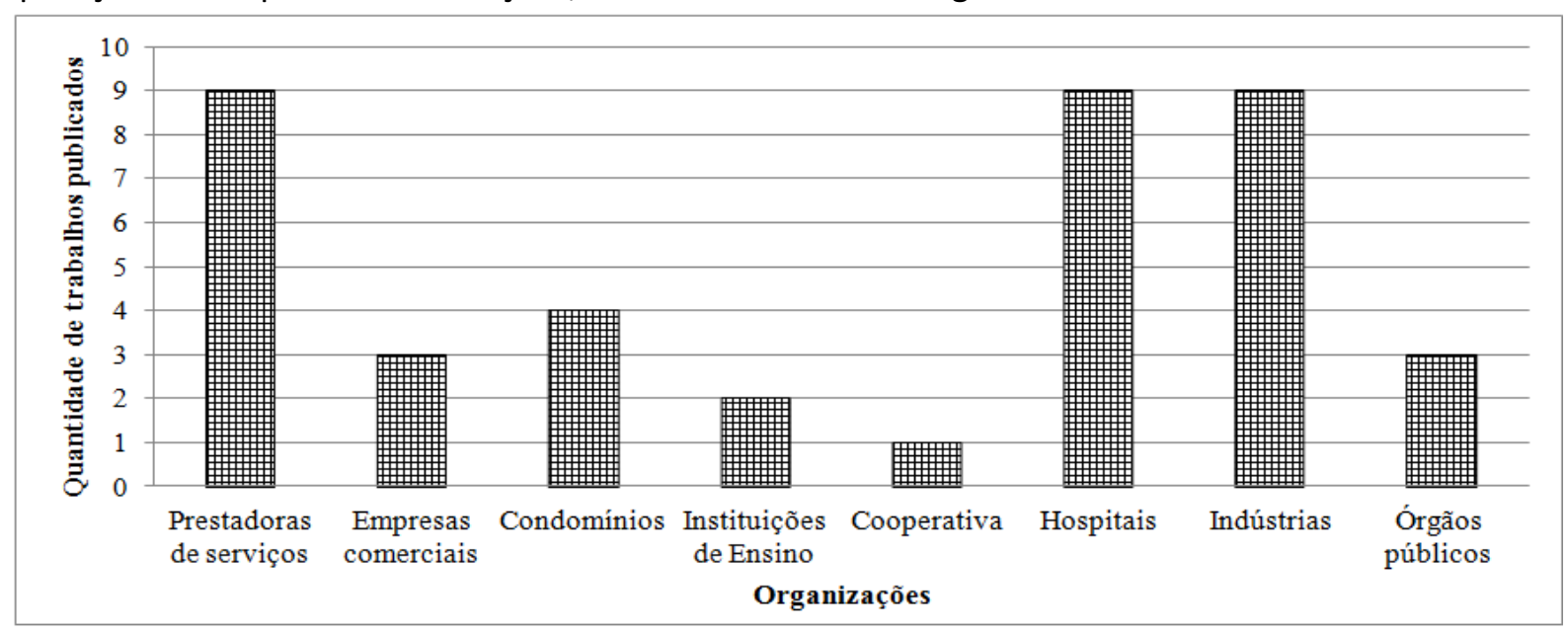

Figura 1: Trabalhos publicados com a utilização da metodologia SICOGEA de 2003 a 2012

Fonte: Adaptado de Vargas et al. (2010b).

Revista de Contabilidade e Controladoria, ISSN 1984-6266

Universidade Federal do Paraná, Curitiba, v. 5, n.3, p. 8-32, set./dez. 2013. 
Não obstante esses estudos envolverem diferentes organizações, são escassas as pesquisas que se preocuparam em verificar a gestão e sustentabilidade ambiental em órgãos públicos, os que têm implicações diretas na sociedade. Entre os estudos realizados, tem-se os de Cunha et al. (2008); Lundberg, Barlfors, Folkeson (2009); Preuss (2009); e Ramos et al. (2009).

Cunha et al. (2008) estudaram de que forma a Prefeitura Municipal de Florianópolis está contribuindo para a gestão do meio ambiente. A pesquisa foi realizada por meio da coleta de dados do referido Órgão, com a aplicação do SICOGEA. Os resultados concluíram que a Prefeitura atingiu um nível satisfatório de sustentabilidade geral, utiliza baixo nível de tecnologia e é comprometida com as questões ambientais.

Lundberg, Barlfors, Folkeson (2009) realizaram um estudo de caso em uma administração ferroviária sueca, para desenvolvimento de um quadro de mensuração do desempenho ambiental (MDA) de organizações do setor público. Os resultados evidenciaram que uma das razões que justificam o desenvolvimento lento da MDA no setor público é a falta de ferramentas e métodos especificamente desenvolvidos para a realidade do setor.

Preuss (2009) observou as formas com que as autoridades do governo da Inglaterra utilizam a função de aquisição para promover o desenvolvimento sustentável. A pesquisa revelou iniciativas do governo, como: contratar organização voluntária no lado social; substituir materiais, produtos e serviços perigosos no lado ambiental; e disseminar informações sobre sustentabilidade ambiental para demonstrar seu compromisso com a sustentabilidade.

Ramos et al. (2009) avaliaram o desempenho da gestão ambiental nas unidades militares portuguesas, por meio da aplicação de questionário com os responsáveis pelas questões ambientais. Os resultados mostraram que a avaliação de desempenho ambiental é uma realidade crescente nas unidades militares portuguesas e que os entrevistados concordam sobre a importância de medir e comunicar o desempenho ambiental com as suas principais atividades.

Aflora-se que a escassez de pesquisas anteriores ambientais em órgãos públicos, enfatiza a importância de se realizarem estudos acerca da gestão e sustentabilidade ambiental de um Órgão Público do Estado de Santa Catarina.

\section{PROCEDIMENTOS METODOLÓGICOS}

A estrutura metodológica desta pesquisa está dividida em cinco partes: (i) enquadramento metodológico; (ii) construção do referencial teórico; (iii) Sistema Contábil Gerencial Ambiental (SICOGEA); (iv) procedimentos para definição dos critérios e subcritérios; e (v) limitações da pesquisa.

\subsection{ENQUADRAMENTO METODOLÓGICO}

O enquadramento metodológico desta pesquisa está segregado sob o enfoque de cinco dimensões: natureza da pesquisa; natureza do objetivo; procedimentos da pesquisa; abordagem do problema; e coleta de dados.

Quanto a sua natureza, a pesquisa é classificada como aplicada, porquanto se destina a investigar e demonstrar hipóteses sugeridas por modelos teóricos definidos. Em relação aos objetivos, é considerada descritiva e exploratória, pois visa descrever e interpretar as características entre as variáveis a partir da coleta de dados e consiste em conhecer com maior profundidade o assunto (BEUREN; RAUPP, 2008; GIL, 2010).

Quanto aos procedimentos da pesquisa, a técnica aplicada neste trabalho é a análise de conteúdo, uma vez que se utiliza de procedimentos sistemáticos e objetivos de descrição do conteúdo das 
informações e de indicadores, permitindo a inferência de conhecimentos relativos às condições de produção/recepção dessas informações (BARDIN, 1994).

Acerca da forma de abordagem do problema, a pesquisa é classificada tanto como qualitativa, quanto quantitativa. De acordo com Richardson (1999) a pesquisa qualitativa busca analisar a interação de certas variáveis, além de compreender e classificar processos dinâmicos vividos por grupos sociais. A pesquisa quantitativa distingue-se pelo emprego da quantificação tanto nas modalidades de coleta de dados, quanto no tratamento delas por meio de técnicas estatísticas.

Em relação à coleta de dados, o trabalho é realizado com amparo em pesquisa de dados que incluem os artigos científicos disponibilizados gratuitamente nas bases de dados indexadas ao Portal de Periódicos da Capes e os dados obtidos da lista de verificação do ente público da pesquisa.

\subsection{CONSTRUÇÃO DO REFERENCIAL TEÓRICO}

O processo utilizado para seleção e análise de referências bibliográficas está dividido em três fases: escolha das bases de dados, seleção de artigos e análise sistêmica (ENSSLIN et al., 2010). A primeira fase fundamenta-se na escolha das bases de dados; a segunda obtém um portfólio de artigos a partir do processo estruturado e fundamentado; e por fim, tem-se a terceira fase para proporcionar a análise sistêmica do portfólio de artigos.

Primeiramente, foi realizada uma consulta à base de dados Periódicos da Capes, área de Ciências Sociais Aplicadas, utilizando as palavras-chave "environmental accounting", "environmental management", associadas a "public institution" e "public sector". Com base nesta estrutura, foram selecionados 223 artigos alinhados com o tema gestão ambiental e setor público publicados de 2002 a 2012. Para atingir esta quantidade de artigos, as fases e etapas foram realizadas de forma sequencial. Outrossim foi realizada pesquisa nas principais revistas de administração, contabilidade, gestão, finanças e negócios, utilizando-se as palavras-chave "gestão ambiental" e "contabilidade ambiental".

A partir dessa amostra inicial, foram lidos todos os resumos, objetivando selecionar os artigos relacionados à gestão e contabilidade ambiental no setor público. Os artigos selecionados compõem o portfólio bibliográfico da pesquisa. Por desfecho, a análise bibliométrica dos artigos do portfólio é uma técnica para o mapeamento dos mais relevantes autores, periódicos e palavras-chave acerca do tema escolhido. Adicionalmente, a referida análise foi utilizada para estudar em detalhe as características bibliográficas de cada artigo, bem como de suas citações.

\subsection{SISTEMA CONTÁBIL GERENCIAL AMBIENTAL (SICOGEA)}

Para atingir o objetivo da presente pesquisa, realizou-se uma análise de conteúdo em um Órgão Público do Estado de Santa Catarina, a partir das informações obtidas nos relatórios de atividades publicados no sítio do referido Órgão e da lista de verificação do SICOGEA - Geração 2, com aplicação in loco.

Nesse passo, introduz-se que o surgimento do SICOGEA objetivou o gerenciamento de aspectos ambientais propostos primeiramente no sistema de Gerenciamento de Aspectos e Impactos Ambientais (GAIA), de autoria de Lerípio (2001). O sistema GAIA é um conjunto de instrumentos e ferramentas gerenciais com foco no desempenho ambiental aplicável aos processos produtivos e na obtenção da sustentabilidade plena (LERÍPIO, 2001). SOUSA et al. (2006) acrescentam que o foco do GAIA inclui 
o desenvolvimento de uma consciência crítica nas pessoas que compõem a organização, no que se refere aos níveis de desperdício de matérias-primas e insumos do processo produtivo, assim como sobre os efeitos produzidos pelos resíduos, pelos efluentes e pelas emissões - ambos gerados nesse processo -, e que são prejudiciais ao ambiente e as pessoas.

O SICOGEA - autoria de Pfitscher (2004) - objetiva gerar informações ao gestor para auxílio a questões inerentes ao meio-ambiente, com menor degradação possível, no intuito de facilitar o controle gerencial dos impactos ambientais gerados pela atividade organizacional. O referido sistema possui três etapas, a se verificar: integração da cadeia produtiva ou da prestação de serviços; gestão de controle ecológico; e gestão da contabilidade e controladoria ambiental. A primeira etapa destinase a identificar o processo produtivo e as necessidades, além de verificar possíveis danos ao meio ambiente em cada atividade. A segunda visa identificar os setores do processo produtivo que possam causar impactos ambientais. Por fim, a terceira etapa tem por finalidade investigar e mensurar aspectos financeiros, econômicos e operacionais, gerando informações que contribuam para o meio ambiente. Esta etapa é segmentada em três fases: investigação e mensuração, informação e decisão.

Após algumas aplicações do SICOGEA, diversos pesquisadores verificaram a necessidade de alguns aperfeiçoamentos (PFITSCHER et al., 2009; COELHO; DI DOMÊNICO; PFITSCHER, 2011). Com efeito, Nunes (2008) apresentou alterações nas etapas do método SICOGEA, tendo maiores mudanças na terceira, resultando tais alterações no desenvolvimento do SICOGEA - Geração 2.

Dentre as alterações do SICOGEA - Geração 2, elencam-se: inclusão de novas nomenclaturas na lista verificação como grupos (chaves e subgrupos); atribuição de escala de pesos nas perguntas de forma a atribuir diferentes graus de importância a cada uma delas; alteração da maneira de calcular os indicadores de sustentabilidade; e estruturação de uma planilha contendo um plano de ação, com o intuito de melhorar duas áreas de maior prioridade (NUNES, 2010).

Em remate, não se perde de vista que nesta pesquisa foi aplicada a fase investigação e mensuração da etapa de gestão da contabilidade e controladoria ambiental do SICOGEA - Geração 2, a fim de verificar a gestão e sustentabilidade ambiental do Órgão sob enfoque.

\subsection{PROCEDIMENTOS PARA DEFINIÇÃO DOS GRUPOS-CHAVES E SUBGRUPOS}

O processo de identificação dos grupos-chaves e subgrupos que compõem a lista de verificação aplicada no Órgão do Estado de Santa Catarina são definidos conforme literatura nacional e internacional - subseção 2.4 - e legislação pertinente a gestão e sustentabilidade ambiental. 0 objetivo de definir o embasamento dos critérios e subcritérios para a contabilização dos eventos e transações que reflitam as interações das entidades com o meio ambiente, justifica-se tendo em vista que além da pressão dos consumidores e das empresas, há também a pressão regulatória.

A normatização para prevenção e conservação dos recursos naturais está prevista na Constituição Federal de 1988, que estabelece: "todos tem direito ao meio ambiente ecologicamente equilibrado, bem de uso comum do povo e essencial à sadia qualidade de vida, impondo-se ao poder público e a coletividade o dever de defendê-lo e preservá-lo para as presentes e futuras gerações." (artigo 225, BRASIL, 1988). No intuito de regulamentar as questões atinentes ao meio ambiente, o governo tem disposto leis, decretos e outros instrumentos normativos que estabelecem políticas de sustentabilidade e responsabilidade socioambiental, conforme Quadro 2. 
Quadro 2: Dispositivos normativos acerca da gestão e sustentabilidade ambiental DISPOSITIVO NORMATIVO REGULAMENTAÇÃO

\begin{tabular}{|l|l|}
\hline Lei no 6.938/1981 & $\begin{array}{l}\text { Estabeleceu a Política Nacional do meio ambiente que objetiva } \\
\text { preservação, melhoria e recuperabilidade da qualidade ambiental } \\
\text { favorável a vida. }\end{array}$ \\
\hline Decreto no 99.658/1990 & $\begin{array}{l}\text { Reaproveitamento, movimentação de material classificado como ocioso ou } \\
\text { recuperável que será cedido a outros órgãos que dele necessitem. }\end{array}$ \\
\hline Decreto no 2.783/1998 & $\begin{array}{l}\text { Proíbe aquisição de produtos ou equipamentos que contenham } \\
\text { Substâncias que Destroem a camada de Ozônio - SDO. }\end{array}$ \\
\hline Decreto no 4.059/2001 & Política Nacional de Conservação e uso racional de energia. \\
\hline Decreto no 4.131/2002 & Medidas emergenciais de redução do consumo de energia elétrica. \\
\hline Decreto no 5.940/2006 & Separação dos resíduos recicláveis descartados e a sua correta destinação. \\
\hline Lei no 12.305/2010 & Instituiu a Política Nacional de resíduos sólidos. \\
\hline Instrução Normativa no 01/2010 & $\begin{array}{l}\text { Regulamentou a utilização de critérios sustentáveis na aquisição de bens e } \\
\text { contratação de obras e serviços. }\end{array}$ \\
\hline
\end{tabular}

Fonte: Adaptado de Luiz et al. (2011) e de Castro, Cruz e Freitas (2011).

O Decreto no 99.658, de 30 de outubro de 1990, apresenta questões relacionadas ao reaproveitamento de materiais, de modo que as ações realizadas de acordo com este decreto podem evitar desperdício e consumo em excesso pelo setor estatal, já que materiais que não serão mais utilizados por um Órgão ou entidade poderão ser reutilizados por outro Órgão ou entidade (CASTRO; CRUZ; FERREIRA, 2011).

O artigo 1 o do Decreto no 2.783, de 17 de setembro de 1998, proíbe a aquisição de produtos ou equipamentos que destroem a camada de ozônio (BRASIL, 1998): "É vedada a aquisição, pelos órgãos e pelas entidades da Administração Pública Federal direta, autárquica e fundacional, de produtos ou equipamentos que contenham ou façam uso das Substâncias que Destroem a Camada de Ozônio SDO.". O Decreto no 4.059, de 19 de dezembro de 2001, regulamenta os níveis máximos de consumo de energia, ou mínimos de eficiência energética, de máquinas, aparelhos e de edificações construídas, devendo estes serem certificados pelo INMETRO do atendimento ao nível máximo de consumo de energia (BRASIL, 2001). Adicionalmente, o Decreto n. 4.131, de, 14 de fevereiro de 2002, os órgãos da Administração Pública Federal direta, deverão observar a meta de consumo de energia elétrica correspondente a $82,5 \%$ do consumo mensal do ano 2000 (BRASIL, 2002).

O Decreto no 5.940, de 25 de outubro de 2006, estabelece a separação dos resíduos recicláveis descartados pelos órgãos e entidades da administração pública federal direta e indireta, na fonte geradora, e a sua destinação às associações e cooperativas dos catadores de materiais recicláveis (BRASIL, 2006). A Instrução Normativa, de 19 de janeiro de 2010, foi criada pelo Ministério do Planejamento, Orçamento e Gestão (MPOG) especifica que a aquisição de bens, contratação de serviços e obras no âmbito federal, deverão conter critérios de sustentabilidade, considerando os processos de extração ou fabricação, utilização e descarte dos produtos e matérias-primas, sem excluir a competitividade.

Dessa maneira, percebe-se que a legislação referente à sustentabilidade ambiental possui ponderações a serem inquiridas aos órgãos públicos, e, portanto, também integram a lista de verificação aplicada neste trabalho. Assim, englobam-se nesta pesquisa tanto os critérios discutidos na literatura, quanto nas obrigações legais. Mesmo que os diplomas normativos sejam aplicáveis a esfera federal, também estenderemos os critérios à esfera estadual, a fim de avaliar o grau de sustentabilidade do Órgão.

\subsection{LIMITAÇÕES DA PESQUISA}


Diversos aspectos dessa pesquisa podem apresentar limitações e vieses em relação aos resultados. Primeiramente, ressalta-se que o presente estudo está delimitado a atender o objetivo de analisar o SICOGEA - Geração 2 do referido Órgão, com ênfase na investigação e mensuração da sustentabilidade e das estratégias ambientais. Em segundo lugar, constitui-se limitação da pesquisa a veracidade das respostas extraídas da lista de verificação aplicada. Não foi feita uma segunda aplicação da referida lista e não ocorreu nenhum fato que influenciasse na resposta de cada critério e subcritério.

Este estudo também limita-se à opinião das pesquisadoras, no que concerne a análise da lista de verificação, terceira etapa, primeira fase do SICOGEA - Geração $2 \mathrm{com}$ aplicação in loco e na interpretação dos fatos, que resulta na identificação de soluções para os pontos deficitários (SOARES, 2003). Em remate, há pretensão de se apresentar uma forma flexível para responder a questãoproblema deste trabalho. Considera-se que outros órgãos e entidades possam identificar outras questões ou aspectos pertinentes tendentes a aperfeiçoar a proposta apresentada nesta pesquisa.

\section{ANÁLISE DOS RESULTADOS}

Nesta seção demonstram-se os resultados da pesquisa. Inicia-se com a apresentação do Órgão Público do Estado de Santa Catarina, seguida de análises da aplicação parcial do SICOGEA no referido Órgão, proposta do plano resumido de gestão ambiental e, finalizando com as estratégias ambientais

\section{I APRESENTAÇÃO DO ÓRGÃO PÚBLICO DO ESTADO DE SANTA CATARINA}

O Estado de Santa Catarina está localizado na Região Sul do Brasil, sendo que sua Capital Florianópolis está situada a $1.850 \mathrm{~km}$ de Buenos Aires, $705 \mathrm{~km}$ de São Paulo e $1.673 \mathrm{~km}$ de Brasília (SANTA CATARINA, 2012). Com seu território de 95,4 mil km², faz fronteira com a Argentina na Região Oeste, ao Norte com o Estado do Paraná e ao Sul com o Estado do Rio Grande do Sul. Em 2010 , sua população era cerca de 6.178 .603 habitantes, representando $22,87 \%$ da população total da Região Sul (IBGE, 2010).

Em Santa Catarina, foi a Constituição de 1947 que previu a criação do Órgão em estudo, responsável pelo controle da aplicação dos recursos públicos no Estado e nos municípios catarinenses, que se concretizou com a Lei no 1366, de 04 de novembro de 1955. As principais incumbências do Órgão estão previstas nos artigos 59 e 113 da Constituição Estadual catarinense, quais sejam: apreciar as contas prestadas, anualmente, pelo governador do Estado e pelos prefeitos municipais, julgar as contas dos administradores e demais responsáveis por recursos públicos, além de verificar a legalidade dos atos de admissão de pessoal (SANTA CATARINA, 1989). Os servidores que compõem o quadro de pessoal ingressam por concurso público e estão organizados em carreiras. Estes devem exercer a fiscalização, inclusive da aplicação de quaisquer recursos repassados pelo Estado a municípios, por meio de convênios, e de subvenções a entidades privadas.

\subsection{APLICAÇÃO PARCIAL DO SICOGEA}

A gestão da contabilidade e controladoria ambiental - aplicada nesta pesquisa - é a terceira etapa do SICOGEA e divide-se em três fases: investigação e mensuração, informação e decisão. Para a efetiva realização dessa etapa, faz-se a investigação dos critérios a serem utilizados com base na literatura e na legislação, a mensuração da sustentabilidade do Órgão em estudo e, por fim, elabora-se um plano resumido de gestão ambiental.

A lista de verificação aplicada possui 76 questões. Para efeitos de análise da sustentabilidade, os subgrupos que compõem a referida lista são: Fornecedores/Compras, Prestação de serviço, Indicadores contábeis e Indicadores gerenciais. Após obter as ponderações realizadas pelos 
respondentes a cada questão, podendo variar de 0 (zero) a 5 (cinco) pontos e o peso atribuído para cada questão, chega-se ao percentual de sustentabilidade. $O$ grau obtido com o cálculo das respostas da lista de verificação é confrontado ao Quadro 3.

Quadro 3: Avaliação da sustentabilidade e do desempenho ambiental

\begin{tabular}{|c|c|c|}
\hline RESULTADO & SUSTENTABILIDADE & DESEMPENHO: CONTROLE, INCENTIVO E ESTRATÉGIA \\
\hline Inferior a $20 \%$ & Péssimo - “P” & Alto impacto pode estar sendo causado ao meio ambiente. \\
\hline Entre $21 \%$ a $40 \%$ & Fraco - "F" & Pode estar causando danos, mas surgem poucas iniciativas. \\
\hline Entre $41 \%$ e $60 \%$ & Regular - "R" & Atende somente a legislação. \\
\hline Entre $61 \%$ a $80 \%$ & Bom - “B” & $\begin{array}{l}\text { Além da legislação, surgem alguns projetos e atitudes que visam } \\
\text { valorizar o meio ambiente. }\end{array}$ \\
\hline Superior a $80 \%$ & Ótimo - “O” & $\begin{array}{l}\text { Alta valorização ambiental com produção ecológica e prevenção } \\
\text { da poluição. }\end{array}$ \\
\hline
\end{tabular}

Fonte: Adaptado de Nunes (2010).

Primeiramente, o grau de sustentabilidade geral obtido foi regular no percentual de $49,32 \%$. 0 referido índice é obtido pela divisão do número de pontos alcançados pelo total de pontos possíveis. Isso significa que o Órgão está mais destinado a atender a legislação acerca da gestão e sustentabilidade ambiental. A Tabela 1 apresenta os índices possíveis e alcançados pelos gruposchave e subgrupos do Órgão em estudo, bem como o escore obtido e o resultado da avaliação de casa um deles.

Tabela 1: Grau de sustentabilidade ambiental

\begin{tabular}{|c|c|c|c|c|}
\hline Grupo-chave e Subgrupos & $\begin{array}{l}\text { Pontos } \\
\text { Possíveis }\end{array}$ & $\begin{array}{c}\text { Pontos } \\
\text { Alcançados }\end{array}$ & $\begin{array}{l}\text { Escore } \\
\text { obtido }\end{array}$ & $\begin{array}{l}\text { Resultado da } \\
\text { Avaliação }\end{array}$ \\
\hline 1 Fornecedores/Compras & 18 & 6,60 & $36,67 \%$ & Fraco \\
\hline 2 Prestação de serviço & 54 & 32,00 & $59,26 \%$ & Regular \\
\hline a) Eco eficiência do serviço prestado & 19 & 12,80 & $67,37 \%$ & Bom \\
\hline b) Nível de tecnologia utilizada & 7 & 3,20 & $45,71 \%$ & Regular \\
\hline $\begin{array}{l}\text { c) Aspectos e impactos ambientais na } \\
\text { prestação de serviço }\end{array}$ & 17 & 12,00 & $70,59 \%$ & Bom \\
\hline d) Gestão de pessoas na instituição & 8 & 4,00 & $50,00 \%$ & Regular \\
\hline e) Disponibilidade de capital & 3 & 0,00 & $0,00 \%$ & Fraco \\
\hline 3 Indicadores contábeis ambientais & 32 & 14,40 & $45,00 \%$ & Regular \\
\hline a) De bens, direitos e obrigações & 9 & 4,20 & $46,67 \%$ & Regular \\
\hline b) De contas de resultado & 7 & 3,40 & $48,57 \%$ & Regular \\
\hline c) De demonstração ambiental específica & 16 & 6,80 & $42,50 \%$ & Regular \\
\hline 4 Indicadores gerenciais & 14 & 5,20 & $37,14 \%$ & Fraco \\
\hline Sustentabilidade ambiental geral & 118 & 58,20 & $49,32 \%$ & Regular \\
\hline
\end{tabular}

Fonte: Adaptado de Nunes (2010).

O grupo-chave Fornecedores/Compras obteve o menor escore de sustentabilidade, pois a maior preocupação do Órgão está centrada na seleção da proposta mais vantajosa para a administração pública. Em geral, não são verificados se os produtos licitados contêm substâncias que destroem a Camada de Ozônio, o que vai de encontro com o que indica o Decreto no 2.783/98. Por outro lado, alguns produtos comprados, quando possível, são reciclados e nos casos de contratação de obras e serviços de engenharia são levados em consideração à economia da manutenção e operacionalização da edificação, bem como a utilização de tecnologias e materiais que reduzam o impacto ambiental conforme sugerido pela Instrução Normativa no 01/10. O grupo-chave Prestação de serviço apresenta o melhor grau de sustentabilidade, mas está classificado como regular. A eco eficiência do serviço prestado possui um índice bom, uma vez que a prestação de serviço não é poluente, a instituição atende às normas referentes à saúde dos colaboradores e são realizadas auditorias ambientais. 
De outro viés, existe pouco investimento em infraestrutura ambiental e institucional, diferentemente do que foi estudado por Oliveira (2003) em Porto Seguro, Icapuí e Fernando de Noronha, onde há desenvolvimento de projetos na área ambiental. Ademais, ao contrário do que sugere Tridapalli et al. (2011), não é feito estimativa para montantes ideais de gastos ambientais.

Quanto ao nível de tecnologia utilizada, o subgrupo possui um escore regular de $45,71 \%$. Os resultados encontrados acerca da complexidade, automação e dependência tecnológica não foram impactantes ao meio ambiente. Outrossim, os aspectos e impactos ambientais demonstram um bom grau de sustentabilidade, uma vez que há pouco consumo e existe reaproveitamento de água no Órgão e são gerados poucos resíduos perigosos (somente no departamento médico).

Apesar dos aspectos ambientais serem, em geral, com avaliação ótima segundo Nunes (2010), não existe efetividade no assunto abordado no Decreto no 5.940/06. Isso porque, pouca quantidade de resíduos descartáveis é reciclada pela instituição, visto que não existem coletores suficientes para tal destinação, e por isso, a maioria dos resíduos não é destinada à coleta para cooperativa habilitada. Adicionalmente, o subgrupo gestão de pessoas obteve um grau de sustentabilidade regular, uma vez que há comprometimento da presidência e do corpo diretivo com a gestão ambiental, mas não existe um acompanhamento com a contabilidade ambiental. Por outro lado, a disponibilidade de capital para investimentos em gestão ambiental é nula, por isso o escore é fraco.

O grupo-chave Indicadores contábeis ambientais apresenta uma sustentabilidade ambiental regular, com $45 \%$ dos pontos possíveis. O resultado dessa avaliação se deve ao fato de que os subgrupos dos indicadores também apresentam resultados regulares na avaliação da sustentabilidade. Quanto ao subgrupo de indicadores de bens, direitos e obrigações, a instituição em estudo não possui gastos com pesquisas, tecnologias e especialistas da área ambiental. Contudo, um fator positivo observado é que a instituição não possui multas e indenizações ambientais no curto e longo prazos. Diferentemente disso, Cunha et al. (2008) observou que na Prefeitura Municipal de Florianópolis, há gastos com especialistas na área ambiental e a Prefeitura apresenta passivos ambientais relativos a empréstimos e financiamentos nesta área.

No que diz respeito aos indicadores de contas de resultado, o Órgão não paga multa nem indenizações por falhas operacionais e acidentes ambientais, mas há pouco consumo de recursos para controle, preservação, proteção ambiental e perda acelerada decorrente de exposição de bens à poluição. Em relação aos indicadores de demonstração específica, a instituição não possui esse tipo de demonstração e não estima passivos contingentes para riscos ambientais. Isso vai de encontro ao estudo de Cunha et al. (2008), uma vez que a Prefeitura Municipal de Florianópolis utiliza o Balanço Social. Ademais, a instituição possui pouca quantidade de resíduos que causam impactos e economiza gastos com pessoal (saúde, improdutividade e absenteísmo). Entretanto, não há controle sob o gasto e o consumo com energia elétrica, de modo a reduzí-los.

O grupo-chave dos Indicadores gerenciais obteve o segundo menor grau de sustentabilidade ambiental. Apesar de a instituição não ser ré em ação judicial referente à poluição ambiental, acidentes ambientais, de não terem ocorridos acidentes ou incidentes ambientais no passado, o Órgão catarinense não trabalha com custos ambientais de prevenção e avaliação, faz poucos investimentos sistemáticos em proteção ambiental e ainda não possui um sistema de gestão ambiental (SGA).

Ao contrário disso, as organizações públicas devem dar respostas às necessidades da sociedade, o que inclui informações sobre os aspectos ambientais, além do mais, as instituições públicas deveriam ser primeiras a tomarem a iniciativa de implantar um eficiente SGA (RAMOS et al. 2007; BARATA; KLIGERMAN; MINAYO-GOMEZ, 2007). Nessa mesma linha, Thomson e Jackson (2007) verificaram que as autoridades governamentais inglesas utilizam variadas abordagens, como a disseminação de compras verdes, fornecedores de informações ou incentivo para adotar o SGA. 
Por desfecho, o resultado da avaliação da sustentabilidade ambiental evidencia que a instituição encontra-se com um desempenho regular. De uma maneira geral, isso demonstra que há aspectos a serem aperfeiçoados com relação ao meio ambiente. Contudo, o Órgão em estudo já está adotando estratégias ambientais para melhorar o referido desempenho ambiental.

\subsection{PLANO RESUMIDO DE GESTÃO AMBIENTAL}

Para melhorar o desempenho dos índices de eficiência ambiental e atender aos aspectos ambientais realizados pelo Órgão, utiliza-se a ferramenta 5W2H (What? Why? When? Where? Who? How? How much?), a qual é a base do plano de gestão ambiental proposto.

Dessa maneira, o plano resumido de gestão ambiental auxilia o Órgão a conferir as metas e objetivos, como também as justificativas, atividades e maneiras de realizar o aperfeiçoamento. Ademais, "o método $5 \mathrm{~W} 2 \mathrm{H}$ é universalmente conhecido e livremente utilizado tanto na academia quanto nas organizações" (NUNES, 2010, p.149).

Para a aplicação do referido plano no grupo-chave Fornecedores/Compras, recomenda-se um projeto que objetive a formação de um cadastro de fornecedores e licitações de bens e serviços com base em critério sustentáveis, a fim de obter uma conduta sustentável dos fornecedores e de selecionar bens, produtos e serviços sustentáveis, conforme Quadro 4.

Quadro 4: Plano resumido de gestão ambiental (Fornecedores/Compras)

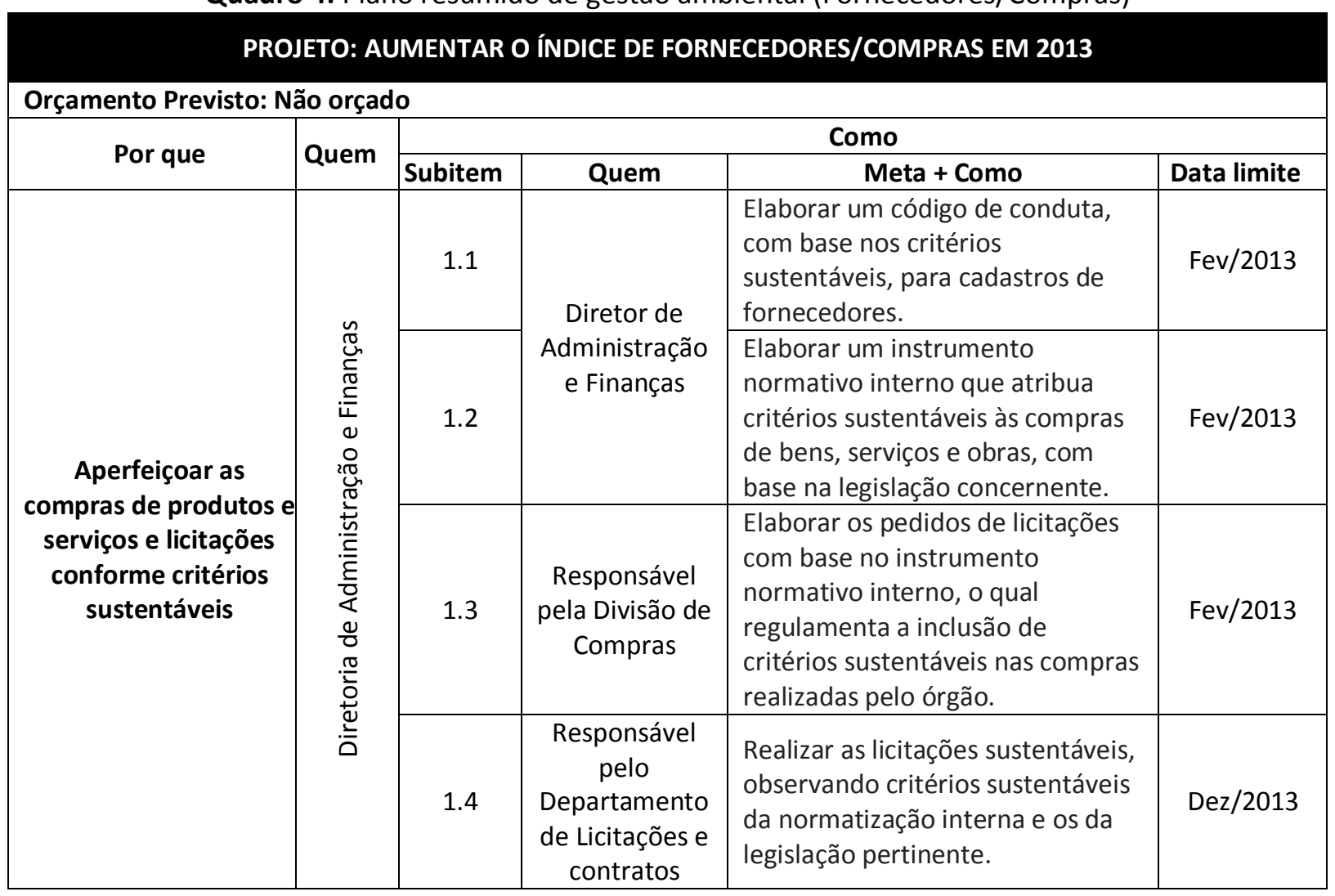

O projeto de aumentar os índices dos Fornecedores/Compras reflete justamente a preocupação ambiental descrita por Tachizawa (2004), de modo que as instituições intrigadas com a gestão ambiental procuram fornecedores que atendam aos seus critérios éticos, além de efetuarem compras de insumos que estejam de acordo com os requisitos ambientais. No grupo-chave Indicadores gerenciais, sugere-se que a instituição pública utilize um sistema de gestão ambiental específico, para que tenha maior controle sobre as ações sociais e ambientais, acerca dos custos de 
prevenção e avaliação ambiental, facilitando a visualização dos aspectos a serem melhorados. 0 Quadro 5 evidencia o plano resumido de gestão ambiental para os referidos indicadores.

Quadro 5: Plano resumido de gestão ambiental (Indicadores gerenciais)

PROJETO: AUMENTAR O ÍNDICE DE INDICADORES GERENCIAIS EM 2013

\begin{tabular}{|c|c|c|c|c|c|}
\hline \multirow{2}{*}{ Por que } & \multirow{2}{*}{ Quem } & \multicolumn{4}{|c|}{ Como } \\
\hline & & Subitem & Quem & Meta + Como & Data limite \\
\hline \multirow{3}{*}{$\begin{array}{l}\text { Desenvolver um } \\
\text { sistema de } \\
\text { gestão ambiental } \\
\text { efetivo para } \\
\text { melhorar o } \\
\text { controle da } \\
\text { sustentabilidade }\end{array}$} & \multirow{2}{*}{ 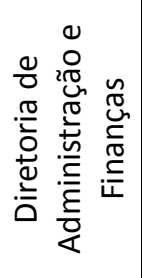 } & 1.1 & \multirow{2}{*}{$\begin{array}{c}\text { Responsável pelo } \\
\text { Departamento de } \\
\text { Contabilidade e } \\
\text { Execução } \\
\text { Orçamentária }\end{array}$} & $\begin{array}{l}\text { Elaborar um orçamento para } \\
\text { investimentos sistemáticos em } \\
\text { proteção e gestão ambiental }\end{array}$ & Fev/2013 \\
\hline & & 1.2 & & $\begin{array}{l}\text { Trabalhar com os custos } \\
\text { ambientais de prevenção e } \\
\text { avaliação. }\end{array}$ & Fev/2013 \\
\hline & 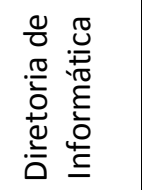 & 1.3 & $\begin{array}{l}\text { Diretor de } \\
\text { Informática }\end{array}$ & $\begin{array}{l}\text { Implantar o sistema de gestão } \\
\text { adequado às necessidades da } \\
\text { instituição. }\end{array}$ & Jun/2013 \\
\hline
\end{tabular}

A implantação de um sistema de gestão ambiental é caracterizada como positiva, pois segundo Knickle (2012) a tecnologia é uma facilitadora da sustentabilidade por meio de softwares e coletas automatizadas de dados acerca da sustentabilidade.

Em remate, a efetividade dos projetos pode acarretar em melhorias significativas na sustentabilidade global do Órgão em estudo. Se todas as metas forem $80 \%$ alcançadas, o grau do grupo-chave Fornecedores/Compras passará de $36,67 \%$ para $71,11 \%$ e o do grupo-chave Indicadores gerenciais evoluirá de $37,14 \%$ para $75,71 \%$ ambos sustentabilidade ambiental ótima. A sustentabilidade ambiental ascenderá de regular com $49,32 \%$ dos pontos possível para boa, com $69,80 \%$ dos pontos possíveis.

\subsection{ESTRATÉGIAS AMBIENTAIS}

Desde o início do ano de 2012 o Órgão do Estado de Santa Catarina tem buscado iniciativas para promover de forma mais eficiente a sustentabilidade para a própria instituição e para a comunidade. Em março de 2012 foi instituída uma Portaria que criou um Grupo de trabalho com o fim de planejar e implantar a adoção de medidas socioambientais no Órgão. Considerou-se a importância da educação ambiental e da conscientização do quadro de pessoal, em relação à preservação dos recursos naturais e à adoção de práticas sustentáveis na prestação do serviço à sociedade.

Posteriormente, em junho de 2012 foi estabelecida outra Portaria que dispõe sobre providências a serem adotadas visando à redução e ao reaproveitamento de papéis no desenvolvimento das atividades do Órgão. A referida diminuição inclui: impressões no modo frente e verso programadas; reaproveitamento dos papéis não utilizados no verso; priorização do uso do e-mail institucional e do telefone como ferramentas de comunicação; entre outras.

A primeira ação realizada pelo Grupo foi a sensibilização e conscientização dos colaboradores (servidores, estagiários, comissionados e terceirizado), voltadas para a situação do impacto ambiental causado pela sociedade, com promoção de palestras e documentário pertinentes aos assuntos de licitações sustentáveis, auditoria ambiental e práticas adotadas em outro Órgão Público. Foram analisados os gastos com copos plásticos descartáveis e não recicláveis, folha de papel tamanho A4 - visto que é a principal matéria-prima utilizada -, energia elétrica e água consumidas no ano de 2011. 
No intuito a mitigar as despesas havidas com copos plásticos, o referido Órgão investiu na compra de canecas personalizadas para todos os servidores, estagiários e terceirizados, uma vez que o levantamento preliminar de 2011 apontou um consumo de mais de 500.000 copos. A fim de reduzir o desperdício e o consumo de folha de papel A4, foi estabelecida a impressão em frente e verso programada pela Diretoria de informática, em todos os documentos elaborados, oficiais ou não, além da indicação pela tramitação processos em meio digital. Adicionalmente, optou-se pela compra de papel A4 reciclado, objetivando a redução do impacto ambiental.

Ademais, o Órgão está em fase de aquisição de coletores de material reciclável identificável por cor (papel, plástico, vidro, metal, pilhas e baterias), que permitirá a separação do material e, posteriormente, o destino à associação/cooperativa habilitada para coleta. Outra estratégia em fase de implantação é a intitulada "Carona solidária", que consiste em uma lista de e-mails em que interessados a dar ou receber carona, podem se comunicar e combinar caronas, visando diminuir o fluxo de veículos e a poluição, tendo em vista que se destinam ao mesmo local de trabalho.

\section{CONCLUSÕES E SUGESTÕES PARA FUTUROS TRABALHOS}

O presente estudo foi norteado pelo objetivo geral de verificar a gestão e sustentabilidade ambiental de um Órgão Público do Estado de Santa Catarina. A fim de atingir este objetivo, utilizou-se da aplicação da primeira fase da terceira etapa do SICOGEA - Geração 2. Por meio das respostas obtidas, verificou-se que o Órgão em estudo atingiu um nível regular de desempenho ambiental no percentual de $49,32 \%$. Isso significa que as práticas ambientais aplicadas estão mais destinadas a atender a legislação acerca da gestão e sustentabilidade ambiental.

Quanto ao objetivo específico de analisar as contribuições ambientais por meio da fase investigação e mensuração do Sistema Contábil Gerencial Ambiental (SICOGEA - Geração 2), o grupo-chave Fornecedores/Compras obteve um resultado de sustentabilidade considerado por Nunes (2010) como fraco, pois a preocupação do Órgão está centrada na seleção da proposta mais vantajosa para a administração pública. De outro viés, alguns produtos comprados são reciclados e nos casos de contratação de obras e serviços de engenharia é levada em consideração a utilização de tecnologias e materiais que reduzam o impacto ambiental, conforme sugerido pela Instrução Normativa n. $01 / 10$.

O grupo-chave Prestação de serviço demonstrou o melhor grau de sustentabilidade, mesmo classificado como regular. Entretanto, há pouco investimento em infraestrutura ambiental e institucional, diferentemente do que foi estudado por Oliveira (2003) em Porto Seguro, Icapuí e Fernando de Noronha, onde há desenvolvimento de projetos na área ambiental. O grupo-chave Indicadores contábeis ambientais apresenta uma sustentabilidade ambiental regular, com $45 \%$ dos pontos possíveis. Quanto aos indicadores de demonstração específica, a instituição não possui tal demonstração e não estima passivos contingentes para riscos ambientais. Isso vai de encontro ao estudo de Cunha et al. (2008), uma vez que a Prefeitura Municipal de Florianópolis utiliza o Balanço Social.

O grupo-chave dos Indicadores gerenciais obteve o segundo menor grau de desempenho ambiental. o Órgão em estudo não trabalha com custos ambientais de prevenção e avaliação e ainda não possui um sistema de gestão ambiental (SGA). Diferente disso, para Ramos et al. (2007), Barata Kligerman e Minayo-Gomez (2007) as organizações públicas devem dar respostas às necessidades da sociedade, além de implantar um eficiente SGA.

Em relação ao objetivo específio de propor um plano resumido de gestão ambiental para o referido Órgão, no intuito a melhorar o desempenho dos índices de eficiência ambiental do Órgão em estudo, utilizou-se a ferramenta $5 \mathrm{~W} 2 \mathrm{H}$, a qual é a base do plano resumido de gestão ambiental proposto. Dessa maneira, no grupo-chave Fornecedores/Compras, recomendou-se um projeto que objetive a 
formação de um cadastro de fornecedores e compras de bens e serviços baseados em critérios sustentáveis. No grupo-chave Indicadores gerenciais, sugeriu-se a utilização de um sistema de gestão ambiental específico, para que exista maior controle sobre as ações sociais e ambientais, facilitando a visualização dos aspectos a serem aperfeiçoados.

Adicionalmente, verificou-se que a efetividade dos projetos pode proporcionar melhorias significativas para a sustentabilidade global. Se todas as metas forem $80 \%$ alcançadas em 2013 , o grau do grupo-chave Fornecedores/Compras passará de $36,67 \%$ para $71,11 \%$ e o do grupo-chave Indicadores gerenciais evoluirá de $37,14 \%$ para $75,71 \%$ ambos sustentabilidade ambiental ótima. Sendo assim, a sustentabilidade ambiental ascenderá de regular com $49,32 \%$ dos pontos possíveis, para boa com $69,80 \%$ dos pontos possíveis.

No que concerne ao terceiro objetivo específico de verificar as estratégias ambientais do Órgão Público estudado para com a sociedade, o resultado da avaliação da sustentabilidade ambiental evidencia que a instituição encontra-se com um desempenho regular para com a sociedade. Apesar disso, o Órgão catarinense em estudo já está adotando estratégias ambientais para melhorar o referido desempenho ambiental, como: redução e reaproveitamento de papéis, aquisição de canecas para mitigar o consumo de copos plásticos, compra e coletores para reciclagem do lixo, e etc.

Para futuras pesquisas, sugere-se: (i) verificar a aplicação das outras fases da etapa de gestão da contabilidade e controladoria ambiental do SICOGEA - Geração 2 neste mesmo Órgão Público; (ii) realizar um estudo comparativo de outros órgãos do Estado de Santa Catarina quanto à sustentabilidade ambiental; e (iii) realizar um estudo idêntico a este em outros órgãos de outros estados brasileiros.

\section{REFERÊNCIAS}

ARIMURA, T. H.; HIBIKI, A.; KATAYAMA, H. Is a voluntary approach an effective environmental policy instrument? A case for environmental management systems. Journal of Environmental Economics and Management, v. 55, p. 281-295, 2008.

BACELO; J.; UHLMANN, V. O.; PFITSCHER, E. D.; SOUZA, M. M. Sustentabilidade ambiental em condomínios: utilização do método SICOGEA para avaliar os aspectos e impactos ambientais a partir de estudos de caso em um condomínio residencial brasileiro.In: CONGRESO TRANSATLÁNTICO, 2., 2010, Lyon.

BARATA, M. M. L.; KLIGERMAN, D. C.; MINAYO-GOMEZ, C. A gestão ambiental no setor público: uma questão de relevância social e econômica. Ciência \& Saúde Coletiva, Rio de Janeiro, v.12, n.1, jan./mar., p. 165-170, 2007.

BARDIN, I. Análise de conteúdo. Lisboa: Edições Setenta, 1994.

BENETTI, J. E.; FIORENTIN, M.; LAVARDA, C. E. F. Diagnóstico da gestão ambiental à luz do Tratado de Kyoto: o caso da unidade produtora de leitões. Revista de Contabilidade e Controladoria, Curitiba, v. 3, n.1, p. 96-110, jan./abr., 2011.

BEUREN, I. M.; RAUPP, F. M. Metodologia da pesquisa aplicável às Ciências Sociais. In.: COLAUTO, R. D.; LONGARAY, A. A.; PORTON, R. A. B.; RAUPP, F. M.; SOUSA, M. A. B.; BEUREN, I. M. (Org.). Como elaborar trabalhos monográficos em contabilidade: teoria e prática. São Paulo: Atlas, 2008. p. 46-97.

BRASIL. Constituição (1988). Constituição da República Federativa do Brasil: promulgada em 5 de outubro de 1988. Disponível em: <http://www.planalto.gov.br/ccivil_03/constituicao/constitui\% C3\%A7ao.htm>. Acesso em: 07 nov. 2012.

BRASIL. Decreto n. 2.783, de 17 de setembro de 1998. Dispõe sobre proibição de aquisição de produtos ou equipamentos que contenham ou façam uso das Substâncias que Destroem a Camada 
de Ozônio - SDO, pelos órgãos e pelas entidades da Administração Pública Federal direta, autárquica e fundacional, e dá outras providências. Disponível em: <http://www.planalto.gov.br/ccivil_03/ decreto/d2783.htm>. Acesso em: 07 nov. 2012.

BRASIL. Decreto n. 4.059, de 19 de dezembro de 2001. Regulamenta a Lei $n^{0} 10.295$, de 17 de outubro de 2001, que dispõe sobre a Política Nacional de Conservação e Uso Racional de Energia, e dá outras providências. Disponível em: <http://www.planalto.gov.br/ccivil_03/decreto/2001/ D4059.htm>. Acesso em: 07 nov. 2012.

BRASIL. Decreto n. 4.131, de 14 de fevereiro de 2002. Dispõe sobre medidas emergenciais de redução do consumo de energia elétrica no âmbito da Administração Pública Federal. Disponível em: < http://www.planalto. gov.br/ccivil_03/decreto/2002/D4131.htm>. Acesso em: 07 nov. 2012.

BRASIL. Decreto n. 5.940, de 25 de outubro de 2006. Institui a separação dos resíduos recicláveis descartados pelos órgãos e entidades da administração pública federal direta e indireta, na fonte geradora, e a sua destinação às associações e cooperativas dos catadores de materiais recicláveis, e dá outras providências. Disponível em: <http://www.planalto.gov.br/ccivil_03/_Ato20042006/2006/Decreto/D5940.htm>. Acesso em: 07 nov. 2012.

BRASIL. Instrução Normativa $n$. 01, de 19 de janeiro de 2010. Dispõe sobre os critérios de sustentabilidade ambiental na aquisição de bens, contratação de serviços ou obras pela Administração Pública Federal direta, autárquica e fundacional e dá outras providências. Disponível em: <http://www.comprasnet.gov.br>. Acesso em: 07 nov. 2012.

CASTRO, J. K.; CRUZ, F.; FREITAS, C. L. Licitações sustentáveis: um estudo nas Instituições Federais de Ensino Superior (IFES) da Região Sul do Brasil. In.: ENCONTRO NACIONAL SOBRE GESTÃO EMPRESARIAL E MEIO AMBIENTE - ENGEMA, 13, 2011, São Paulo. Anais... São Paulo, 2011, CD.

CARROLL, K. A. Property rights and managerial decisions in for-profit, nonprofit and public organizations. Comparative theory and policy. Gordonville, VA, USA: Palgrave Macmillan, 2004.

CHEN, C.; MONAHAN, G. E. Environmental safety stock: the impacts of regulatory and voluntary control policies on production planning, inventory control, and environmental performance. European Journal of Operational Research, v. 207, p. 1280-1292, 2010.

CHIANG, C. Insights into current practices in auditing environmental matters. Managerial Auditing Journal, v. 25, p. 912-933, 2010.

COELHO, E.; DI DOMÊNICO, D.; PFITSCHER, E. D. Análise de sustentabilidade ambiental: estudo de caso em uma fábrica de estofados. Revista de Informação Contábil, v. 6, n. 1, p. 66-84, jan/mar, 2011.

CRUZ, C. F.; MARQUES, A. L.; FERREIRA, A. C. S. Informações ambientais na contabilidade pública: reconhecimento de sua importância. In.: SOUTH AMERICAN CONGRESS ON SOCIAL AND ENVIRONMENTAL ACCOUNTING RESEARCH, 1., 2009, Rio de Janeiro. Anais... Rio de Janeiro: Universidade Federal do Rio de Janeiro, 2009.

CUNHA, C. T. N.; PFITSCHER, E. D.; NUNES, J. P. O.; ALBERTON, L.; NERES, D. A gestão da Prefeitura Municipal de Florianópolis quanto ao meio ambiente com o auxílio da contabilidade e controladoria ambiental. In.: SIMPÓSIO DE GESTÃO DA INOVACAÇÃO TECNOLÓGICA, 25., 2008, Brasília.

ENSSLIN, L.; ENSSLIN, S. R.; LACERDA, R. T. O.; TASCA, J. E. ProKnow-C, knowledge, development process - constructivist. Processo técnico com patente de registro pendente junto ao INPI. Brasil, 2010.

GIL, A. C. Como elaborar projetos de pesquisa. 5. ed. São Paulo: Atlas, 2010. 
SANTA CATARINA. Informações sobre o Estado de Santa Catarina. Disponível em: <http://www.sc.gov.br/conteudo/santacatarina/geografia/paginas/localizacao.html>. Acesso em: 03 nov. 2012.

HESS, D. Catalyzing Corporate Commitment to Combating Corruption. Journal of Business Ethics, v. 88, p. 781-790, 2009.

IBGE - Instituto Brasileiro de Geografia e Estatística. Dados do censo. Diário Oficial da União. Publicado em 04 de novembro de 2010. Disponível em: <http://www.censo2010.ibge.gov.br/ dados_divulgados/index.php?uf=42>. Acesso em: 03 nov. 2012.

KNICKLE, K. Environmental sustainability for manufacturers in 2012: part I. Supply Chain Management Review, Feb., 2012.

KOPPENJAN, J. F. M.; ENSERINK, B. Public - private partnerships in urban infrastructures: reconciling private sector participation and sustainability. Public Administration Review, mar./abr., 2009.

LERÍPIO, A. Á. GAIA - Um método de gerenciamento de aspectos e impactos ambientais. 2001. $174 \mathrm{f}$. Tese (Doutorado em Engenharia de Produção) - Programa de Pós-Graduação em Engenharia da Produção, Universidade Federal de Santa Catarina, Florianópolis, 2001.

LIMONGI, B.; KREMER, B. V.; CASAGRANDE, M. D. H.; PFITSCHER, E. D.; NUNES, J. P. O. A contabilidade ambiental como instrumento de auxílio na gestão: aplicação parcial do SICOGEA em uma Instituição de Ensino. In: CONGRESSO DE CONTABILIDADE E AUDITORIA, 12, Aveiro. Anais... Aveiro: Universidade de Aveiro, 2008. p. 1082-1098.

LODHIA, S. K. Accountants' responses to the environmental agenda in a developing nation: an initial and exploratory study on Fiji. Critical Perspectives on Accounting, v. 14, p. 715-737, 2003.

LUIZ, L. C.; RAU, K.; FREITAS, C. L.; PFITSCHER, E. D. Agenda Ambiental na Administração Pública (A3P) e práticas de sustentabilidade: um estudo aplicado em um Instituto Federal de Educação, Ciência e Tecnologia (IFECT). In: ENCONTRO NACIONAL SOBRE GESTÃO EMPRESARIAL E MEIO AMBIENTE ENGEMA, 13, 2011, São Paulo. Anais... São Paulo, 2011, CD.

LUNDBERG, K.; BALFORS, B.; FOLKESON, L. Framework for environmental performance measurement in a Swedish public sector organization. Journal of Cleaner Production, v. 17, p. 1017-1024, 2009.

MARQUES, V. E. ; PFITSCHER, E. D. ; GALLON, A. V. Análise da Gestão Ambiental em meio às práticas operacionais com base na aplicação parcial do SICOGEA: estudo de caso. In: SIMPÓSIO DE ADMINISTRAÇÃO DA PRODUÇÃO, LOGÍSTICA E OPERAÇÕES INTERNACIONAIS, 12., 2009, São Paulo. Anais...

MIA, A. H. The role of government in promoting and implementing environmental management accounting: the case of Bangladesh. Implementing Environmental Management Accounting, p. 297320, 2005.

MOFFAT, A.; AUER, A. Corporate Environmental Innovation (CEI): a government initiative to support corporate sustainability leadership. Journal of Cleaner Production, v. 14, p. 569-600, 2006.

NUNES, J. P. O. Um aporte ao sistema contábil gerencial ambiental: elaboração e aplicação parcial do novo sistema em clínica hospitalar. Florianópolis, 2010, 241 f. Dissertação (Mestrado) - Programa de Pós-Graduação em Contabilidade, Universidade Federal de Santa Catarina, 2010.

OLIVEIRA, J. A. P. Governmental responses to tourism development: three Brazilian case studies. Tourism Management, v. 24, p. 97-110, 2003.

PFITSCHER, E. D. Gestão e sustentabilidade através da contabilidade e controladoria ambiental: estudo de caso na cadeia produtiva de arroz ecológico. Florianópolis, 2004, 252 f. Tese (Doutorado 
em Engenharia de Produção) - Programa de Pós-Graduação em Engenharia de Produção, Universidade Federal de Santa Catarina, 2004.

PFITSCHER, E. D.; NUNES, J. P. O.; BESEN, F.; TRÊS, D. L.; VAN BELLEN, H. M. Contribuições de melhoria para o Sistema Contábil Gerencial Ambiental - SICOGEA. Revista del Instituto Internacional de Costos, n. 5, p. 119- 140, jul./dic., 2009.

POKORNY, J. Database architectures: current trends and their relationships to environmental data management. Environmental Modelling \& Software, v. 21, p. 1579-1586, 2006.

POLAZ, C. N. M.; TEIXEIRA, B. A. N. Indicadores de sustentabilidade para a gestão municipal de resíduos sólidos urbanos: um estudo para São Carlos (SP). Engenharia Sanitária \& Ambiental, v. 14, n. 3, p. 411-420, 2009.

PREUSS, L. Addressing sustainable development through public procurement: the case of local government. Supply Chain Management: An International Journal, v. 14, p. 213-223, 2009.

PRIZZIA, R. The impact of development and privatization on environmental protection: an international perspective. Environment, Development and Sustainability, v. 4, n. 3, p. 315-331, 2002.

RAMOS, T. B.; ALVES, I.; SUBTIL, R.; MELO, J. J. Environmental performance policy indicators for the public: the case of the defence sector. Journal of Environmental Management, v. 82, p. 410-432, 2007.

RAMOS, T. B.; ALVES, I.; SUBTIL, R.; MELO, J. J. The state of environmental Performance evaluation in the public sector: the case of the Portuguese defence sector. Journal of Cleaner Production, v.17, p. 36-52, 2009.

RICHARDSON, R. J. Pesquisa social: métodos e técnicas. 3. ed. São Paulo: Atlas, 1999.

ROSA, F. S.; PFITSCHER, E. D.; STEIGER, M. M.; NUNES, J. P. O.; SILVA, G. J. A Implantação do SICOGEA: sistema contábil gerencial ambiental em um hospital. In.: CONGRESSO BRASILEIRO DE CUSTOS, 15., Curitiba, 2008. Anais...

SALDANO; P. M.; CASAGRANDE, M. H.; UHLMANN, V. O. Análise de sustentabilidade ambiental: estudo de caso em uma clínica odontológica municipal. In: SEMINÁRIOS EM ADMINISTRAÇÃO, 13., 2010, São Paulo. Anais...

SANTA CATARINA. Constituição (1989). Constituição do Estado de Santa Catarina promulgada em 05 de outubro de 1989. Disponível em: <http://www.alesc.sc.gov.br/portal/legislacao/docs/ constituicaoEstadual/CESC\%202012\%20-\%2063\%20e\%2064\%20emds.pdf>. Acesso em: 07 nov. 2012.

SILVA, E. A.; ROSA, F. S.; PFITSCHER, E. D. A importância da contabilidade no processo de gestão ambiental de uma empresa do setor moveleiro: estudo de caso utilizando o SICOGEA. In.: SIMPÓSIO DE ENGENHARIA DE PRODUÇÃO, 16., 2009, Bauru. Anais...

SOARES, E. Metodologia científica: lógica, epistemologia e normas. São Paulo: Atlas, 2003.

SOARES, S. V.; LANZARIN, J.; PFITSCHER, E. D. Investimentos sociais e ambientais de uma instituição financeira: evidenciação por meio de Balanço Social. Revista de Contabilidade e Controladoria, Curitiba, v. 3, n.2, p. 57-77, mai./ago., 2011.

SOUSA, M. A. B.; SANTO, F. F.; LERÍPIO, A. Á.; SELIG, P. M.; BOMFÁ, C. R. Z. Gerenciamento de aspectos e impactos ambientais em uma empresa fabricante de tubos, tubetes e conicais. Revista Produção Online, v. 6, n. 1, p. 92-107, 2006. 
SOUZA, M.A.; RÁSIA, K. A.; JACQUES, F. V. S. Evidenciação de informações ambientais pelas empresas integrantes do Índice de Sustentabilidade Empresarial - ISE. Revista de Contabilidade $e$ Controladoria, Curitiba, v. 2, n. 1, p. 51-139, jan./abr., 2010.

TACHIZAWA, T. Gestão Ambiental e responsabilidade social corporativa. São Paulo: Atlas, 2004.

THOMSON, J.; JACKSON, T. Sustainable procurement in practice: lessons from local government. Journal of Environmental Planning and Management, v. 50, n. 3, p. 421-44, 2007.

TRIDAPALLI, J. P.; BORINELLI, B.; CAMPOS, M. F. S. S.; CASTRO, C. Análise dos gastos ambientais no setor público brasileiro: características e propostas alternativas. Revista de Gestão Social e Ambiental, São Paulo, v. 5, n. 2, mai./ago., p. 79-95, 2011.

VARGAS, A. B.; PFITSCHER, E. D.; NASCIMENTO, C.; NUNES, J. P. O. Análise do sistema de gestão ambiental em uma empresa de cosméticos por meio da utilização do SICOGEA - Sistema Contábil Gerencial Ambiental. Enciclopédia biosfera, v. 6, p. 15-29, 2010a.

VARGAS, A. B.; PFITSCHER, E. D.; NASCIMENTO, C.; NUNES, J. P. Mapeamento dos aspectos considerados relevantes em estudos que abordam a aplicação do SICOGEA. In.: CONGRESSO INTERNACIONAL DE ADMINISTRAÇÃO, 2010, Ponta Grossa. Anais... Ponta Grossa: ADMPG, 2010b.

WCED - UNITED NATIONS WORLD COMMISSION ON ENVIRONMENT AND DEVELOPMENT. OU common future (The Brundtland Report). Oxford: OUP, 1987.

WILSON, D.; GAME, C. Local Government in the United Kingdom. 4th ed. Palgrave, Basingstoke, 2006. 
GRUPO-CHAVE 1 - FORNECEDORES/COMPRAS

1. As matérias primas compradas são oriundas de recursos renováveis?

2. Os fornecedores apresentam processos produtivos que causam impacto ao meio ambiente e aos seres humanos? (inversa)

3. Os fornecedores estão comprometidos com o meio ambiente?

4. Os principais fornecedores da instituição são certificados pelas normas ambientais ISO 14.001? (Sistema de Gestão Ambiental efetivo)

5. Os fornecedores dão garantia de qualidade?

6. Os fornecedores dão garantias de segurança?

7. As compras da instituição incluem, quando possível, produtos/serviços recicláveis?

8. Nos casos de contratação de obras e serviços de engenharia são levados em consideração à economia da manutenção e operacionalização da edificação, bem como a utilização de tecnologias e materiais que reduzam o impacto ambiental?

9. Os fornecedores da instituição se obrigam a reciclar os seus produtos usados?

10. São verificados se os equipamentos ou produtos licitados contêm substâncias que destroem a Camada de Ozônio (exceto essenciais)?

11. As compras perecíveis estão sujeitas a uma data limite de utilização?

12. Nos casos de alienação de materiais, as vendas são realizadas mediante concorrência, leilão ou convite?

\section{GRUPO-CHAVE 2 - PRESTAÇÃO DE SERVIÇO}

A) ECOEFICIÊNCIA DO SERVIÇO PRESTADO

13. A prestação de serviço realizada pela instituição é poluente?

14. A prestação de serviço demanda um alto consumo de energia?

15. A instituição atende as normas referentes à saúde e segurança dos colaboradores (servidores, estagiários, comissionados e terceirizados)?

16. Existe na instituição, um manual de segurança interna, que acompanha o processo de prestação de serviços?

17. Existe geração de resíduos durante a prestação de serviços?

18. Os resíduos gerados são reaproveitados na instituição?

19. São realizadas auditorias ambientais e avaliação de desempenho ambiental?

20. A instituição investe em infraestrutura ambiental institucional? (Desenvolve projetos que envolvem saneamento, abastecimento de água e restauração ambiental, entre outros).

21. São definidos critérios para estimar montantes ideais de gastos ambientais?

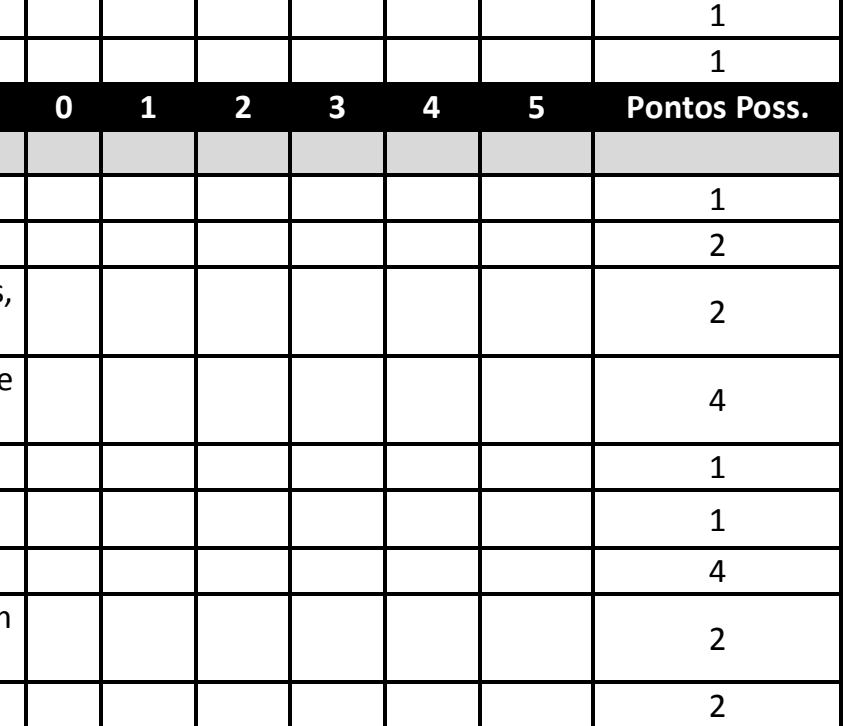

Universidade Federal do Paraná, Curitiba, v. 5, n.3, p. 8-32, set./dez. 2013. 


\section{B) NÍVEL DE TECNOLOGIA UTILIZADA}

22. A tecnologia, na prestação de serviço, apresenta grau de complexidade elevado?

23. A tecnologia, na prestação de serviço, apresenta alto índice de automação (demanda uma baixa densidade de capital e trabalho)?

24. A tecnologia, na prestação de serviço, demanda a utilização de insumos e matéria primas perigosas?

25. A tecnologia, na prestação de serviços, demanda utilização de recursos não renováveis?

26. A tecnologia, na prestação de serviço, é autóctone (capaz de ser desenvolvida, mantida e aperfeiçoada com recursos próprios)?

27. A tecnologia, na prestação de serviços, apresenta uma dependência da instituição em relação a algum fornecedor ou parceiro?

\section{C) ASPECTOS E IMPACTOS AMBIENTAIS NA PRESTAÇÃO DE SERVIÇO}

28. Existe um alto consumo de água no processo de prestação de serviço?

29. Existe um alto consumo de água total na instituição?

30. A fonte hídrica utilizável é comunitária?

31. Existe algum reaproveitamento de água na instituição?

32. Há separação dos resíduos recicláveis descartados pela instituição?

33. A coleta dos resíduos recicláveis é realizada por associação/cooperativa habilitada?

34. Há controle por parte da instituição para amenizar a poluição sonora?

35. São gerados resíduos perigosos durante o processo de prestação de serviços?

36. Existe algum tipo de reaproveitamento de papel e outros no processo de prestação de serviços?

37. Existe na instituição um plano de prevenção em caso de incidente grave ambiental?

38. As normas de segurança e meio ambiente são rigorosamente respeitadas pelos funcionários?

\section{D) GESTÃO DE PESSOAS NA INSTITUIÇÃO}

39. A presidência se mostra efetivamente comprometida com a gestão ambiental?

40. O corpo gerencial se apresenta efetivamente comprometido com a gestão ambiental?

41. A mão de obra empregada é altamente especializada, também em contabilidade ambiental?

42. A criatividade é um dos pontos fortes da instituição e de seus colaboradores?

43. Existe uma política de valorização do capital intelectual?

44. Existe algum acompanhamento da área de Gestão de Pessoas com a Contabilidade Ambiental?

E) DISPONIBILIDADE DE CAPITAL

45. Existe capital próprio disponível para investimentos em gestão ambiental?

46. Existem restrições cadastrais ou legais para a permissão de empréstimos para investimentos em gestão ambiental?

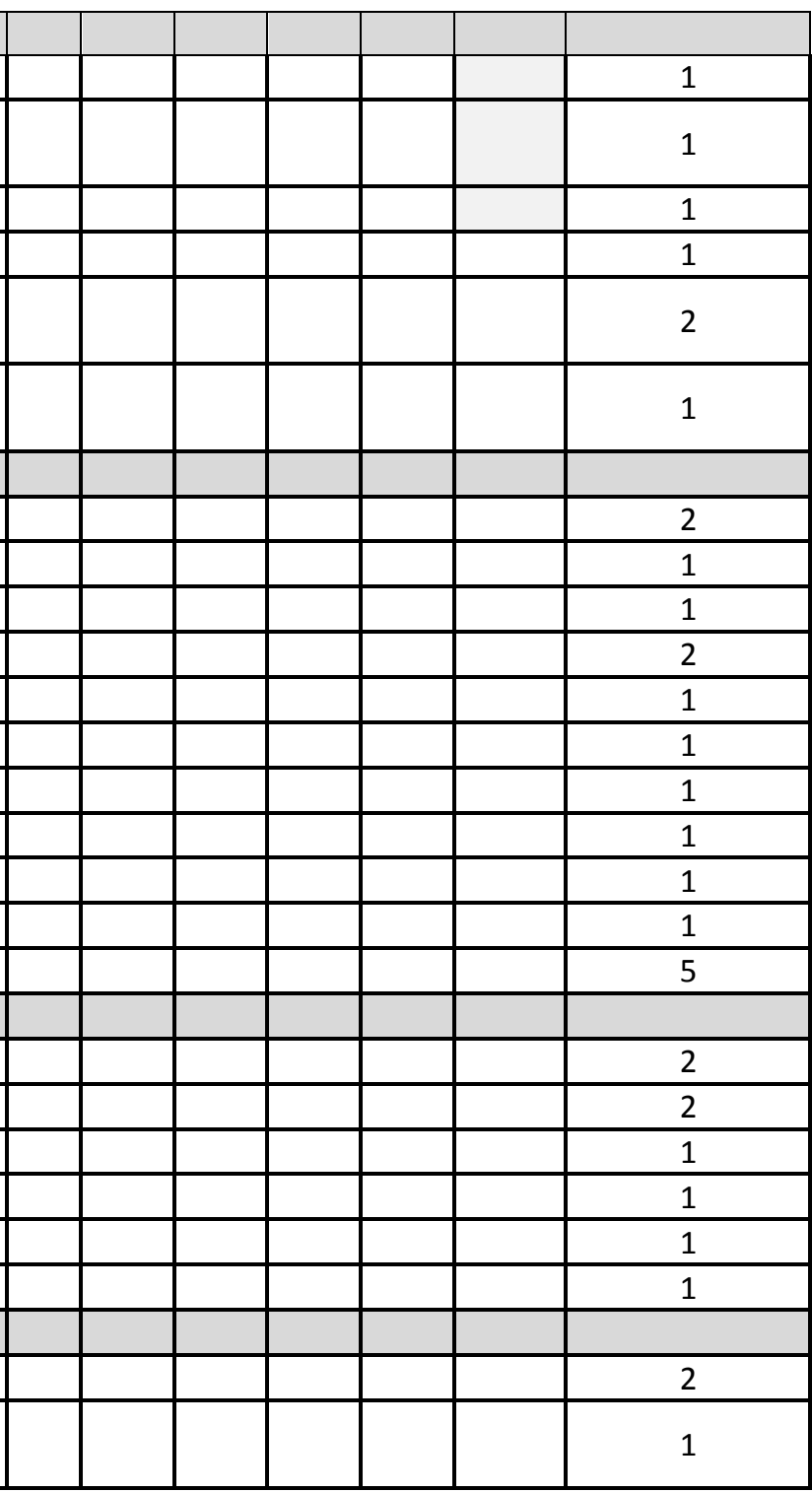


GRUPO-CHAVE 3 - INDICADORES CONTÁBEIS

A) INDICADORES AMBIENTAIS DE BENS E DIREITOS E OBRIGAÇÕES

47. A instituição possui bens em uso no processo de proteção, controle, preservação e recuperação ambiental?

48. A instituição possui gastos com pesquisas e desenvolvimento de tecnologias ambientais?

49. A instituição possui passivos ambientais, relativos a empréstimos e financiamentos de investimentos na gestão ambiental?

50. A instituição possui multas e indenizações ambientais a curto prazo?

51. A instituição possui salários e encargos de especialistas da área ambiental?

52. A instituição possui passivos ambientais, relativos a empréstimos e financiamentos de investimentos na gestão ambiental a Longo Prazo?

53. A instituição possui multas e indenizações ambientais a longo prazo?

B) INDICADORES AMBIENTAIS DE CONTAS DE RESULTADOS

54. Existe consumo de recursos para controle, preservação, proteção ambiental e perda acelerada decorrente de exposição de bens à poluição?

55. O consumo de recursos para controle, preservação, proteção ambiental e perda acelerada decorrente de exposição de bens à poluição tem se mantido constante?

56. A instituição paga taxas, contribuições e demais gastos relacionados com a área ambiental?

57. A instituição paga multas e indenizações por falhas operacionais, como infração à legislação ou direito de terceiros?

58. A instituição paga multas e indenizações por acidentes ambientais; perdas por exposição de pessoas e bens à poluição?

C) INDICADORES DE DEMONSTRAÇÃO AMBIENTAL ESPECÍFICA

59. A instituição possui Demonstração ambiental específica? Ex: Balanço Social

60. A instituição estima passivos contingentes e/ou cria provisões para risco ambiental?

61. Existe aquisição de imobilizados?

62. A instituição paga insumos utilizados para redução dos impactos ambientais?

63. A instituição possui gastos com divulgação na área ambiental?

64. A instituição possui economia de energia elétrica (82,5\% do consumo mensal tendo por referência o ano 2000)?

65. A instituição possui economia em transportes (combustível, lubrificante, etc)?

66. A instituição possui economia de matérias primas?

67. A instituição possui economia de gastos com pessoal? (saúde, improdutividade, absenteísmo, etc).

68. A instituição possui grande quantidade de resíduos que causam impacto?

GRUPO-CHAVE 4 - INDICADORES GERENCIAIS

Revista de Contabilidade e Controladoria, ISSN 1984-6266

Universidade Federal do Paraná, Curitiba, v. 5, n.3, p. 8-32, set./dez. 2013.

\begin{tabular}{|c|c|c|c|c|c|c|}
\hline $\mathbf{0}$ & 1 & 2 & 3 & 4 & 5 & Pontos Poss. \\
\hline & & & & & & 1 \\
\hline & & & & & & 1 \\
\hline & & & & & & 1 \\
\hline & & & & & & 2 \\
\hline & & & & & & 1 \\
\hline & & & & & & 1 \\
\hline & & & & & & 2 \\
\hline & & & & & & \\
\hline & & & & & & 1 \\
\hline & & & & & & 1 \\
\hline & & & & & & 2 \\
\hline & & & & & & 1 \\
\hline & & & & & & 2 \\
\hline & & & & & & \\
\hline & & & & & & 2 \\
\hline & & & & & & 1 \\
\hline & & & & & & 1 \\
\hline & & & & & & 2 \\
\hline & & & & & & 1 \\
\hline & & & & & & 3 \\
\hline & & & & & & 3 \\
\hline & & & & & & 1 \\
\hline & & & & & & 1 \\
\hline & & & & & & 1 \\
\hline & 1 & 2 & 3 & 4 & 5 & os $\mathrm{P}$ \\
\hline
\end{tabular}


69. A instituição já obteve benefícios e/ou premiações pela atuação na valorização do meio ambiente?

70. A instituição é ré em alguma ação judicial referente à poluição ambiental, acidentes ambientais e/ou indenizações trabalhistas?

71. Já ocorreram reclamações sobre aspectos e impactos do processo de prestação de serviços por parte da sociedade/comunidade?

72. Ocorreram acidentes ou incidentes ambientais no passado?

73. A instituição possui um sistema de gestão ambiental?

74. São realizados investimentos sistemáticos em proteção ambiental?

75. A instituição trabalha com custos ambientais de prevenção?

76. A instituição trabalha com custos ambientais de avaliação?

\begin{tabular}{|l|l|l|l|l|l|l|l|}
\hline & & & & & & & 2 \\
\hline & & & & & & & 3 \\
\hline & & & & & & & 1 \\
\hline & & & & & & & 1 \\
\hline & & & & & & & 1 \\
\hline
\end{tabular}

